\title{
UMA ANÁLISE DO SETOR DE PREVIDÊNCIA COMPLEMENTAR BRASILEIRO*
}

\author{
Leandro Willer Pereira Coimbra ${ }^{* *}$
}

Silvia Harumi Toyoshima ${ }^{* * *}$

\begin{abstract}
RESUMO Este trabalho teve como objetivo analisar o setor de previdência complementar, observando os níveis de concentração, os efeitos das políticas de fiscalização, o grau de eficiência das empresas e as barreiras à entrada e à saída de firmas no setor. A metodologia básica consistiu no cálculo do Índice de Gini e no Método de Análise Envoltória de Dados. As principais conclusões da pesquisa foram que as empresas de tamanho médio são as mais eficientes do setor e estão ganhando participação no mercado, enquanto as cinco maiores empresas continuam, também, ampliando suas participações, a despeito de serem mais ineficientes. Tal fenômeno se explica pela sua ligação com grandes bancos, que se apresentam como uma barreira a novas empresas.
\end{abstract}

Palavras-chave: previdência complementar; análise de eficiência; estratégia; fiscalização

Código JEL: L22 firm organization and market structure

\section{AN ANALISYS FOR BRASILIAN COMPLEMENTARY PROVIDENCE SECTOR}

ABSTRACT The objective of this paper was to analyze the complementary providence sector, observing the concentration level, the effects of fiscalization policies, the degree of firm efficiency and the barriers to entry and exit for firms in the sector. The basic methodology consists in calculating the Gini Index and in Data En-

* Artigo enviado em 20 de maio de 2008 e aprovado em 14 de setembro de 2009. Os autores agradecem à Fapemig pela concessão de bolsa de iniciação científica ao aluno.

** Bolsista de iniciação científica em Ciências Econômicas pela Universidade Federal de Viçosa, e-mail: wleandru@yahoo.com.br

*** Professora associada do Departamento de Ciências Econômicas na Universidade Federal de Viçosa, e-mail: htsilvia@ufv.br 
velopment Analysis Method. The main conclusions of this research were that the medium sized firms are the most efficient of the sector, gaining market participation, while the five biggest firms also continue to increase their participations, despite being more inefficient. This phenomenon is explained by the links of these firms with big banks, that constitutes as a barrier for new firms.

Key words: complementary providence; efficiency analysis; strategy; fiscalization 


\section{INTRODUÇÃO}

O presente estudo pretendeu analisar o mercado de previdência privada aberta, investigando a estrutura do setor, as condutas e as estratégias das empresas atuantes, bem como seu nível de eficiência, para a permanência, crescimento e maturação no mercado.

A constituição de 1988 apresenta a seguridade social como tarefa do estado, compreendendo "um conjunto integrado de ações de iniciativa dos poderes públicos e da sociedade, destinadas a assegurar os direitos relativos à saúde, à previdência e à assistência social” (Brasil, art. 194, capítulo II, 1988).

A previdência como função do estado vem trazendo prejuízos para a sociedade de um modo geral, não apenas pelos déficits que vem acumulando durante anos, mas também pelo seu potencial distributivo de transferência de renda, que vem sendo questionado pelos estudiosos (Moura et al., 2007).

É nesse cenário de questionamento quanto ao desempenho da previdência social que surge a previdência privada, ou complementar, como solução apontada por estudiosos, pela mídia e, muitas vezes, apoiada também pelos governantes (Jardim, 2003).

A previdência privada é uma forma de realocação da renda, que tem como objetivo a manutenção de um padrão de vida difícil de ser alcançado pelo sistema da previdência social. Sua principal função, assim, é permitir a manutenção da qualidade de vida do trabalhador no período de sua improdutividade, propiciando a continuidade de uma renda próxima à do período de atividade.

No entanto, devido ao seu sistema de financiamento baseado na capitalização dos fundos, a previdência privada se tornou um instrumento financeiro com grande potencial de captação de poupança de longo prazo, sendo essa característica, atualmente, vista por especialistas e estudiosos como a principal vantagem de um sistema complementar ou, como em alguns países, substituto da previdência social, proporcionando a base para o crescimento econômico sustentável do país.

A previdência privada aberta é representada no mercado pelas sociedades seguradoras autorizadas a atuar com planos de previdência e pelas entidades de previdência aberta. Elas têm por objetivo "instituir e operar planos 
de benefício de caráter previdenciário concedidos em forma de renda continuada ou pagamento único acessível a qualquer pessoa física" (art. 36 da LC no 109/2001). ${ }^{1}$

O setor possui, atualmente, rigorosa fiscalização, que tem por objetivo desvincular a falta de credibilidade existente anteriormente à reforma de 1977, quando todo o sistema foi reestruturado após uma onda de falências de empresas que não possuíam qualquer regulação por parte do estado. A partir disso, os órgãos reguladores responsáveis vêm propiciando ferramentas cada vez mais eficientes, que permitem total segurança aos adquirentes desses planos. Muitos estudiosos consideram essas medidas essenciais para o bom desempenho do setor; outros, contudo, maléficas, argumentando que contribuem para a depreciação do livre-mercado. Segundo Carvalho (2006), os países-membros da OCDE estão em um processo de sujeitar o mercado de seguros mais a uma supervisão do que a uma grande regulação, como observado no mercado brasileiro.

A análise do setor, à luz dos estudos da Organização Industrial, possibilita demonstrar como a interferência dos organismos responsáveis está se retratando no comportamento e na evolução do setor. Segundo Mason (1939), as estratégias (condutas) das firmas se baseiam na estrutura do cenário em que a firma está inserida, determinando, assim, o retorno alcançado por elas. Esse autor rompeu radicalmente com as teorias microeconômicas até então existentes. Abandonou o uso de estudos paramétricos, voltando sua teoria para resultados empíricos, a fim de evidenciar as particularidades das empresas, assim como suas estratégias. Essa análise permite entender a atual situação do setor, assim como os caminhos que ele está seguindo, possibilitando reconsiderar e inovar condutas atuais, sejam essas condutas tanto das empresas quanto dos órgãos fiscalizadores.

Existem poucos estudos voltados para o mercado de previdência privada. Nos últimos anos, dois trabalhos buscaram medir a eficiência técnica das seguradoras atuantes no mercado de previdência aberta. Adicionalmente, essa medida de eficiência foi relacionada à sua forma de atuação junto ao sistema bancário (Silva e Azevedo, 2004; Silva, 2006). Os resultados em ambos os trabalhos demonstraram que empresas que pertencem a um conglomerado financeiro são mais eficientes, o que lhes confere maiores vantagens competitivas, refletindo-se em maior lucratividade. Outro estudo, de Abo- 
lins (2000), procurou avaliar as estratégias utilizadas no setor com base em estudos de casos, focando apenas em algumas empresas. Verificou-se um maior empenho, por parte dessas empresas, em expandir o número de consumidores potenciais por meio da diversificação de produtos, do uso da Internet e de uma administração mais transparente dos fundos, sendo os dois últimos fatores identificados como aqueles que possibilitam maior proximidade com o cliente.

Os estudos mencionados focaram a questão das estratégias, traçando as condutas utilizadas, de forma geral ou mais específica, em cada empresa.

A preocupação com a estrutura e o nível de concorrência foi apresentada por Faria (2007), que estudou o setor de seguros como um todo, principalmente os seus níveis de concentração. Segundo o autor, o mercado segurador apresenta indícios de um mercado de concorrência monopolística, inexistindo barreiras legais, restritivas à entrada de novas firmas no mercado.

As pesquisas apresentadas procuraram estudar as estratégias do setor sem considerar sua estrutura.

Nesse sentido, a principal contribuição do presente estudo foi analisar as estratégias das empresas atuantes no ramo de previdência privada aberta a partir de uma investigação da estrutura do setor e de sua evolução nos últimos anos, possibilitando um melhor entendimento das atuais estratégias.

O presente artigo procurou, assim, investigar a organização e a estruturação do setor previdenciário, observando os níveis de concentração, os efeitos das políticas de fiscalização, o grau de eficiência das empresas e as possíveis barreiras à entrada e à saída existentes. Buscou-se identificar, ainda, as características e estratégias que favorecem as empresas líderes do mercado, assim como as práticas utilizadas por elas, mas que são prejudiciais ao setor. Desse modo, pretendeu-se fornecer informações às empresas atuantes para a formulação de novas estratégias, assim como aos órgãos reguladores, para a formulação de políticas para o setor.

Partiu-se do pressuposto de que a participação das empresas no mercado de previdência não está diretamente associada ao seu desempenho operacional, e a análise de outros fatores, como a ligação das seguradoras a um grupo ou instituição forte em face dos consumidores, se relacionará melhor com sua participação no mercado.

Este trabalho foi dividido em cinco seções, incluindo esta introdução. A primeira seção corresponde a uma discussão da teoria microeconômica 
da Organização Industrial no setor de previdência privada aberta. A segunda seção traz a descrição da metodologia utilizada. Na terceira seção, são apresentados os principais resultados. E, por fim, a última seção trata das principais conclusões da pesquisa.

\section{A ORGANIZAÇÃO INDUSTRIAL E O SETOR DE PREVIDÊNCIA PRIVADA ABERTA}

A intensidade da competição em determinados setores não pode ser considerada fruto do acaso ou da sorte (Porter, 1999). A teoria microeconômica da Organização Industrial introduziu o conceito de Estrutura, Conduta e Desempenho (E-C-D), a partir da obra seminal de Mason (1939), que postula a ideia de que as estratégias (condutas) das firmas se baseiam na estrutura do cenário em que a firma está inserida, determinando, assim, o retorno alcançado por elas. Bain (1959) retomou os estudos de Mason, formalizando-os e buscando uma relação mais direta entre a estrutura e o desempenho.

A análise da estrutura leva às limitações das condutas. Nesse conjunto de atributos se encontra o princípio do entendimento de toda a mecânica desenvolvida pelo E-C-D. Para a análise do mercado de previdência privada, englobaram-se como fatores característicos da estrutura do mercado:

(1) a concentração do mercado;

(2) a existência das barreiras à entrada e à saída de empresas;

(3) o número e tamanho relativo das empresas; e

(4) a diferenciação dos produtos.

Desses fatores, as barreiras à entrada ganharam a atenção e o foco de diversos estudos, por exemplo o de Baumol (1982), que desenvolveu a Teoria dos Mercados Contestáveis, que é entendido como aquele que não possui barreiras à entrada, permitindo mobilidade às empresas para entrar no mercado quando os lucros do setor se apresentarem altos, reduzindo o poder de monopólio. Da mesma forma, deve haver facilidade de saída do mercado, para eliminar as tentativas de retaliação por parte das empresas atuantes.

Especificamente para o mercado de previdência privada, Kato (2000) apresenta algumas barreiras à entrada de novas empresas, sendo elas: 
- A diferenciação do produto ocorre pela reputação e tradição de uma empresa. A característica do produto previdenciário, como um bem que será usufruído a longo prazo, implica maior confiabilidade em instituições mais antigas e já conhecidas, fazendo com que esse seja um fator de grande importância na escolha pelo cliente. Dessa maneira, as novas empresas inseridas no setor devem inicialmente transmitir essa segurança aos consumidores em potencial, sendo o tempo um fator importante para obter confiabilidade.

- Acesso aos canais de distribuição. Aproximar-se do cliente requer a contratação de corretores autônomos e a instituição de escritórios próprios, o que implica custos altos.

- Custos menores das empresas com maior experiência e detentora de grande parcela do mercado. Esse tipo de empresa já está bem situada, conhecendo as formas de atuação e os caminhos mais simples de sua administração. Essa barreira se apresenta comum a vários segmentos da economia, não sendo um problema específico desse setor.

As condutas utilizadas pelas empresas corresponderam a uma segunda parte do trabalho. As manobras pelo posicionamento entre as empresas atuantes no presente instante configuram uma análise complexa, devido às características particulares desenvolvidas em cada setor e espaço de tempo, necessitando de buscas empíricas para uma compreensão do cenário.

Em 1979, a Xerox Corporation desenvolveu um processo exatamente para a compreensão dos posicionamentos das concorrentes, denominado benchmarking competitivo. Utilizou-se da comparação entre os produtos produzidos pela Xerox e os produzidos pelas concorrentes, apontando, assim, suas falhas e pontos fracos.

Benchmarking, segundo Camp (1993, p. XV), "é a busca pelas melhores práticas que conduzem uma empresa à maximização da performance empresarial. Estabelecer alvos operacionais com base nas melhores práticas possíveis da indústria...”.

A compreensão das vantagens e desvantagens dos concorrentes ou dos líderes de um setor permite melhorar as práticas de atuação, com o estabelecimento de metas reais e embasadas em observações reais e possíveis de alcançar. 
Porter (1996) afirma que as empresas com piores índices de conduta devem, além de seguir as estratégias das líderes, apresentar outras que possibilitem uma concorrência não direta, isto é, buscar caminhos que façam das estruturas internas uma possibilidade, e não uma restrição.

A investigação das condutas das empresas do setor de previdência privada foi elaborada a partir de um estudo de benchmarking para destacar, assim, os rumos do setor e as estratégias de concorrência "não direta" das empresas menores.

\section{METODOLOGIA}

\subsection{Considerações iniciais}

A metodologia do presente artigo compreende as seguintes partes:

( $1^{\text {a }}$ a busca da compreensão de como se organiza e se estrutura o setor previdenciário foi elaborada por meio de análise da legislação e dos mecanismos legais de defesa da estrutura do setor;

$\left(2^{a}\right)$ a estrutura das empresas foi testada pela mensuração da evolução dos níveis de concentração, buscando comparar esses resultados com os resultados da análise de eficiência, obtidos por meio do método Análise Envoltória de Dados (DEA); e

( $\left.3^{a}\right)$ por último, foram apresentadas algumas características julgadas relevantes para o desempenho das arrecadações previdenciárias por meio de comparação entre as empresas desse mercado.

Os dados foram obtidos na Federação Nacional de Seguros (Fenaseg) e na Superintendência de Seguros Privados (Susep), além de se fazer uso dos boletins anuários de resultados, disponibilizados também pela Fenaseg, para o período 1999-2007.

Em seguida, são apresentados os métodos de Gini e de Concentração Parcial, que mensuram o grau de concentração do setor, e o DEA, para a análise de eficiência das empresas.

\section{2 Índices de concentração}

Para uma melhor compreensão do nível de competição de um setor, faz-se necessária uma análise do nível de concentração. Para tal análise, foram utilizados os Índices de Concentração Parcial (CR) e o Índice de Gini. A es- 
colha desses dois índices se deu pela diferença de suas formas de análises: enquanto o primeiro investiga a situação das empresas líderes, o outro analisa a concentração do setor como um todo. A análise conjunta de ambos os índices permite, assim, um melhor entendimento do grau de concentração do setor.

Além da escolha dos índices, houve uma preocupação com a seleção das variáveis utilizadas nos testes. No caso do setor previdenciário, foram utilizadas as contribuições previdenciárias retidas pelas empresas, que consistem no total das contribuições arrecadadas com os planos de previdência, menos as transferências cedidas para outras entidades, mais as transferências aceitas de outras entidades. Essa variável foi escolhida como representativa da atuação das empresas no mercado, levando em consideração apenas as responsabilidades realmente existentes, o que exclui os repasses de arrecadação feitos para outras empresas. E sua escolha se deu pelo fato de o tamanho da arrecadação indicar o poder da empresa no mercado.

\subsubsection{Concentração parcial (CR)}

O Índice de Concentração Parcial aponta para a concentração das parcelas de participação das empresas líderes, ${ }^{2}$ em comparação ao crescimento geral do setor. Esse índice não leva em consideração o número de empresas existentes, por isso é um Índice de Concentração Parcial.

Foram adotados o CR4 e o CR8, que representam as proporções das quatro e das oito maiores empresas, respectivamente. A variação dessas concentrações foi apresentada para os anos 1999 a 2007.

O índice de concentração parcial pode ser expresso da seguinte forma:

$$
C R_{K}=\sum_{I=1} E_{i}
$$

onde Ei é a parcela do mercado (em termos percentuais) da i-ésima firma, sendo $k$ igual a 4 para CR4 e igual a 8 para CR8.

\subsection{2 Índice de Gini}

O Índice de Gini, diferentemente do Índice de Concentração Parcial, apresenta a concentração do setor como um todo, relativamente a uma distribuição teórica perfeitamente equitativa. 
A representação do coeficiente de Gini é dada pela seguinte expressão, conhecida como Fórmula de Brown:

$$
G=\left|1-\sum_{K=1}^{K=n-1}\left(X_{k+1}-X_{K}\right)\left(Y_{k+1}+Y_{K}\right)\right|
$$

onde $G$ = coeficiente de Gini; $X=$ proporção acumulada da variável "população"; e $Y=$ proporção acumulada da variável "renda".

Para o que na fórmula se chama genericamente de "população" e "renda", neste estudo, especificamente, serão utilizadas as variáveis "número de empresas" e "contribuição previdenciária retida", respectivamente.

O índice varia entre 0 e 1 , apresentando valores próximos a 1 para altos níveis de concentração e valores mais próximos a 0 , quanto menor for o nível de concentração.

Os testes também foram aplicados para os anos 1999 a 2007.

\subsection{Análise de eficiência}

O estudo da eficiência relativa é feito por meio da estimativa de uma fronteira eficiente, que funciona como modelo teórico de eficiência para as unidades estudadas. As ineficiências na produção dessas unidades foram medidas pelas distâncias em que se encontram da fronteira.

A fronteira de eficiência pode ser elaborada por meio de dois grupos de modelos diferentes: os modelos paramétricos e os não paramétricos.

Os modelos paramétricos são amparados por métodos econométricos que se baseiam na estimativa de uma função de produção teórica e ideal, formulada a partir de dados médios e estimados das empresas. A dificuldade desse modelo está em estimar tal função.

Como alternativa para contornar essa dificuldade, surgiu a análise não paramétrica, que consiste na comparação do processo de produção das empresas, identificando aquelas mais eficientes, que passam a ser padrão de referência da eficiência do setor. Com base nessas empresas, estabelece-se a ineficiência das outras e são indicados os caminhos necessários para que estas últimas alcancem melhores níveis de eficiência. 


\subsubsection{Análise Envoltória de Dados - DEA}

A Análise Envoltória de Dados (DEA $)^{3}$ é uma técnica não paramétrica que utiliza a programação matemática para análise das eficiências relativas, tendo sido elaborada pela primeira vez em 1978, por Charnes et al. (Gomes e Baptista, 2004).

Esse modelo considera que as empresas, ou mais apropriadamente denominadas Unidades Tomadoras de Decisão (DMUS), ${ }^{4}$ possuem mais que variações em torno da média, possuindo verdadeiros benchmarks, isto é, unidades reais que atuam de maneira eficiente e que servem de exemplo para as demais empresas consideradas ineficientes (Ghilardi, 2006).

Segundo Gomes e Baptista (2004), a pressuposição fundamental na técnica DEA é de que a capacidade de uma DMU, de transformar uma quantidade $\mathrm{Y}$ de produto (output) utilizando uma quantidade $\mathrm{X}$ de insumo (input), poderia ser alcançada pelas outras DMUs que realizam tarefas similares, caso estas atuassem de forma eficiente em sua produção.

A figura 1 mostra a capacidade de seis DMUs produzirem uma unidade de produto Y utilizando diferentes combinações de insumos X1 e X2. Dessa forma, a DMU 3, por exemplo, para produzir uma unidade de $Y$ necessita de quatro unidades de $\mathrm{X} 2$ e quatro unidades de X1, enquanto a DMU 2 necessita também de quatro unidades de X2, mas apenas duas unidades de X1. Isso significa que a DMU 2 é mais eficiente na produção de Y que a DMU 3.

Figura 1: Fronteira das DMUs eficientes

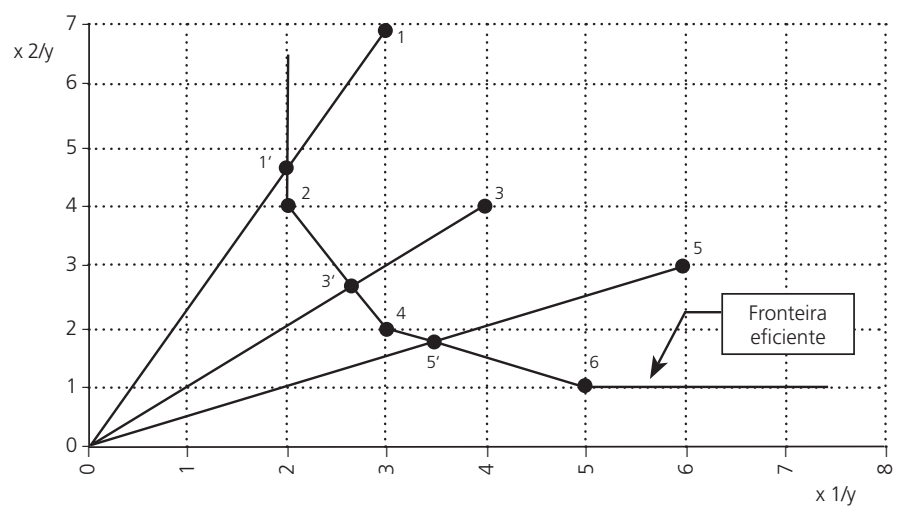


A fronteira de eficiência, para o exemplo, é formada pelas DMUs 2, 4 e 6, sendo as DMUs 1, 3 e 5 consideradas ineficientes. Utilizando-se de movimentos radiais, as DMUs ineficientes são projetadas na fronteira de eficiência, originando DMUs virtuais, sendo essas combinações das benchmarks que possibilitarão à DMU ineficiente tornar-se eficiente. No caso da DMU 3, suas benchmarks são as DMUs 2 e 4, que originarão a DMU virtual 3', que possui uma combinação de insumos eficiente, servindo de modelo para a DMU 3.

Nesse exemplo, buscou-se melhorar a eficiência das DMUs, mantendo-se o nível de produção e reduzindo-se a quantidade de insumos. Essa forma de orientação é chamada de orientação insumo. Existe, no entanto, uma segunda forma de orientar as DMUs, denominada orientação produto, que enfatiza o aumento do produto sem alterar o nível dos insumos utilizados.

O primeiro modelo de DEA elaborado foi o CCR, também conhecido como CRS (Constant Returns to Scale), que faz uso da programação matemática para solucionar problemas mais complexos (maior número de variáveis). O modelo aqui apresentado está na forma de programação fracionária e possui orientação output.

A eficiência é determinada pela otimização da divisão entre a soma ponderada das entradas (input virtual) e a soma ponderada das saídas (output virtual), procurando pesos para cada variável (entrada ou saída) de cada DMU, de forma que esses pesos aplicados às DMUs eficientes gerem uma razão igual a 1. Para as outras DMUs, o valor dessa razão será sempre maior que 1, dado que esse valor implica quanto os produtos devem ser multiplicados, mantendo-se constantes os recursos, para que ela possa atuar de forma eficiente. Essas condições são apresentadas pela equação a seguir:

$$
\begin{aligned}
& \operatorname{Min}\left(h_{0}\right)=\left(\frac{\sum_{j=1}^{r} v_{i} x_{i_{0}}}{\sum_{i=1}^{s} u_{j} y_{j_{0}}}\right) \\
& \text { s.a. } \\
& \sum_{i=1}^{r} v_{i} x_{i_{0}} \\
& \sum_{i=1}^{s} u_{j} y_{j_{0}} \\
& v_{i}, u_{j} \geq 0, \forall i, j k
\end{aligned}
$$


Sendo:

$h_{0}$, a 1/eficiência da $\mathrm{DMU}_{0}$, i.e., o valor multiplicado pelo produto mantendo constantes os insumos que levam a $\mathrm{DMU}_{0}$ a um nível de produção eficiente;

$v_{i}$ e $u_{j}$, os pesos de inputs $i, i=1, \ldots, r$, e outputs $j, j=1, \ldots, s$;

$x_{i k}$ e $y_{j k}$, os inputs $i$ e outputs $j$ da DMU $k, k=1, \ldots, n$; e

$x_{i 0}$ e $y_{j 0}$, os inputs $i$ e outputs $j$ da $\mathrm{DMU}_{0}$.

Com o intuito de facilitar a solução do modelo, ele foi transformado em um problema de programação linear, em que o denominador da função objetivo deve ser igualado a 1. Nesse modelo, as variáveis de decisão são os pesos $v_{i}$ e $u_{j}$, e ele pode ser expresso da seguinte forma:

$$
\begin{aligned}
& \operatorname{Min}\left(h_{0}\right) \\
& =\sum_{i=1}^{r} v_{i} x_{i 0} \\
& \text { s.a. } \\
& \sum_{j=1}^{s} u_{j} y_{j 0}=1 \\
& \sum_{j=1}^{s} u_{j} y_{j k}-\sum_{i=1}^{r} v_{i} x_{i k} \geq 0, \forall k \\
& u_{j} v_{j} \geq 0, \forall j, i
\end{aligned}
$$

Nos resultados do DEA com orientação output, as DMUs que apresentarem resultados acima dos $100 \%$ serão consideradas ineficientes, enquanto aquelas que apresentarem resultados iguais a $100 \%$ serão as eficientes. Assim sendo, por exemplo, uma DMU com um resultado de 125\% descreve uma situação em que sua eficiência é igual a $80 \%(1 / 1,25)$, ou que sua produção pode ser aumentada em $25 \%$, caso a mesma quantidade de insumo seja aplicada eficientemente.

Em 1984, com o objetivo de analisar economias com rendimentos de escalas variáveis, foi criado o modelo DEA BCC, ${ }^{5}$ também denominado VRS (Variable Return to Scale). O modelo considera que acréscimos de inputs no processo produtivo poderão ocasionar acréscimos não proporcionais aos outputs. 
A equação a seguir apresenta esse modelo com orientação produto (output):

$$
\begin{aligned}
& \operatorname{Max}\left(h_{0}\right) \\
& \text { s.a. } \\
& x_{i 0}-\sum_{k=1}^{n} x_{i k} \lambda_{k} \geq 0, \forall i \\
& -h_{0} y_{j 0}+\sum_{k=1}^{n} y_{j k} \lambda_{k} \geq 0, \forall j \\
& \sum_{k=1}^{n} \lambda_{k}=1 \\
& \lambda_{k} \geq 0, \forall k
\end{aligned}
$$

$\lambda_{k}$ é a contribuição da $\mathrm{DMU}_{k}$ na formação da $\mathrm{DMU}_{0}$ sob análise.

Acreditando na existência de ganhos de escala no setor e fazendo uso dos recursos disponibilizados pelo EMS, os modelos serão rodados considerando rendimentos crescentes na produção. ${ }^{6}$

Para rodar o modelo, ainda é necessário selecionar os dados referentes aos insumos e produtos de cada DMU a ser analisada. Em Cooper et al. (2000, apud Gomes e Baptista, 2004) são destacados pontos que auxiliam na escolha desses dados:

- os dados de insumos e produtos devem assumir valores não negativos para todas as DMUs;

- os insumos, produtos e escolhas das DMUs devem refletir o interesse do pesquisador nos componentes que entrarão na avaliação da eficiência relativa das DMUs;

- a unidade de medida dos insumos e produtos não necessita ser a mesma, ou seja, pode-se ter, por exemplo, um insumo medido em dias de serviço, outros em litros, quilos, gastos monetários etc.; e

- preferencialmente, o número de variáveis (soma de insumos e produtos) não deve superar em um terço o número de observações.

Considerando esses pontos e o objetivo do trabalho, foram selecionadas todas as 48 empresas que atuaram com previdência privada nos anos 2005, 2006 e 2007, sendo 22 seguradoras e 26 entidades abertas de previdência 
complementar. Foram desconsideradas aquelas que saíram ou entraram nesse período. Para a análise específica das seguradoras, duas empresas foram retiradas da amostra, por se constituírem em outliers.

Os insumos e produtos utilizados foram: ${ }^{7}$

Inputs

- despesas comerciais;

- despesas administrativas;

- despesas financeiras; e

- despesas tributárias.

Output

- rendas de contribuições retidas e de prêmios ganhos.

Para a resolução dos cálculos necessários, foi utilizado o programa Efficiency Measurement System - EMS, versão 1.3.0.

\section{ANÁlisE doS RESULTADOS}

O número de empresas atuantes no mercado de previdência aberta se elevou muito desde a estabilização da economia com o Plano Real em 1994, quando as seguradoras com atuação em previdência privada aberta eram apenas quatro. O que se observa ao longo dos últimos anos, contudo, é uma redução gradual de novas instituições, com uma consequente queda no número total de seguradoras e das Entidades Abertas de Previdência Complementar - EAPCs. A tabela 1 mostra essa evolução.

Em relação às barreiras existentes para a entrada de novas empresas no setor de previdência privada aberta, observa-se que há apenas algumas,

Tabela 1: Instituições atuantes no ramo de previdência privada aberta ${ }^{8}$

\begin{tabular}{llccc}
\hline Ano & Número de empresas & Entradas & Saídas & Saldo \\
\hline 2000 & 77 & 18 & 9 & 9 \\
\hline 2001 & 77 & 8 & 8 & 0 \\
\hline 2002 & 71 & 5 & 11 & -6 \\
\hline 2003 & 68 & 4 & 7 & -3 \\
\hline 2004 & 64 & 6 & 10 & -4 \\
\hline 2005 & 58 & 5 & 11 & -6 \\
\hline 2006 & 56 & 0 & 2 & -2 \\
\hline 2007 & 50 & 2 & 8 & -6 \\
\hline
\end{tabular}

Fonte: Dados Susep, 2008 (site e boletins). 
mas suficientemente poderosas para inibir o livre acesso de empresas nesse mercado.

A primeira delas, de difícil transposição, é o acesso aos canais de distribuição do produto. A atuação em todo o território nacional, juntamente com a necessidade da seleção de consumidores em potencial, implica altos custos.

Outra barreira observada, que será mais bem evidenciada no restante do trabalho, é a existência de grandes empresas que possuem grande controle do mercado e que estão vinculadas a marcas fortes no mercado financeiro. São formas de atuação utilizadas pelas grandes empresas que restringem a entrada de novas empresas.

Ambas as barreiras fazem do mercado de previdência complementar aberta um mercado não contestável. $\mathrm{Na}$ área legal, contudo, esse cenário se modifica, inexistindo barreiras significantes à entrada. Há diversas medidas de incentivo a uma maior concorrência no setor.

A circular da Susep no 260, de 8 de julho de 2004, regulamenta a constituição de novas empresas no setor de previdência aberta. Em seu art. $7^{\circ}$, essa circular estabelece que, para autorização e funcionamento de uma seguradora atuante no ramo de vida e previdência, exige-se um capital mínimo, isto é, um montante de capital que deverá ser mantido para que possa operar sob regime de solvência. Os valores exigidos são determinados pela Resolução da CNSP no 155/2006.

Esses valores poderiam indicar uma barreira à entrada, porém são considerados ínfimos quando relacionados aos valores registrados pelas empresas atuantes no mercado. Dentre as seguradoras que apresentaram os menores valores retidos de contribuições, a Cardif do Brasil Vida e Previdência S/A detinha um patrimônio líquido, em 2007, de cerca de quatro vezes o valor mínimo estipulado, ou seja, mais de $\mathrm{R} \$ 60.000 .000,00$ (sessenta milhões de reais).

O intuito desse capital mínimo é trazer segurança ao sistema, consistindo em uma das possíveis formas de trazer às pequenas e novas empresas a confiabilidade exigida para atuar no mercado, embora em um primeiro momento possa parecer uma barreira a esse tipo de empresa.

Os órgãos reguladores do sistema previdenciário apresentam grande preocupação com a segurança e credibilidade do setor, promovendo grande 
intervenção neste. O que se observa, contudo, é uma tendência da política exercida por esses órgãos de promover uma maior semelhança entre os produtos previdenciários, aproximando-os de um mercado de bens sem diferenciação.

O estabelecimento de limites para investimentos dos fundos previdenciários, também, apresenta essa mesma característica. Sua principal função está na redução dos riscos. Porém, as entidades possuem um menor espaço para diferenciação de investimentos, tornando as rentabilidades dos fundos das empresas mais semelhantes.

Outro fator que promove maior semelhança entre os produtos é a caracterização dos planos e dos contratos, que ficam sujeitos às determinações dos órgãos públicos responsáveis, não permitindo acordos e negociações entre as pessoas envolvidas, ou seja, entre as instituições e o adquirente do produto. Os planos surgem com nomes diferentes em cada instituição, mas suas características são semelhantes, considerando que todos os planos necessitam de aprovação normativa.

A própria segurança, dada por essas ferramentas e outras, como a portabilidade (que possibilita a um participante trocar de plano previdenciário, levando os recursos acumulados para aquele de sua preferência) e a blindagem (que obriga as empresas a constituírem fundos isolados dos riscos da companhia, a fim de que, mesmo no caso de quebra da empresa, os recursos dos fundos permaneçam intactos) (Borges, 2006), leva as empresas à semelhança no quesito segurança e confiabilidade, e essa mesma segurança, se passada ao consumidor, permitirá que ele desconsidere esse fator um diferencial de sua escolha.

\subsection{A concentração do setor}

Com a redução de novas empresas entrantes no mercado, nos últimos anos, associada à saída de várias empresas no mesmo período, o número de instituições previdenciárias vem se reduzindo, sugerindo uma concentração no setor a partir de 2002.

Essa "aparente concentração" só pode ser verificada com o uso de uma série de índices de concentração que demonstrem como evoluiu a parcela de participação de cada empresa. 
A figura 2 apresenta os resultados da evolução da concentração do setor pelos dois índices: Índice de Gini e Índice de Concentração Parcial, este último voltado à análise das quatro e das oito maiores empresas do setor.

Os resultados apontam uma alta concentração no setor, sendo que para o ano de 2007 a arrecadação total das quatro maiores empresas chegava a quase $70 \%$ (as oito maiores empresas controlavam $85 \%$ das contribuições para o mesmo ano).

O CR4 e o CR8 informam, ainda, que a parcela de participação das empresas líderes (as quatro e as oito maiores, respectivamente) na arrecadação de contribuições previdenciárias elevou-se acima do crescimento geral do setor, a partir de 2002. Esse resultado aponta para uma concentração do setor nos últimos anos, conforme já indicado pela análise da tabela 1 .

O Índice de Gini, contudo, indica uma leve desconcentração geral do setor, caindo quase 5\% entre 1999 e 2006, havendo uma pequena elevação em 2007, causada, principalmente, por algumas fusões importantes ocorridas no ano.

A evolução dos índices aplicados apenas às sociedades seguradoras se assemelha àquela observada para todo o setor. Contudo, os níveis de desconcentração apontados pelo Índice de Gini foram mais acentuados nesse ramo específico, reduzindo-se em quase $10 \%$ no período de 1999 a 2006, o que representa o dobro do que ocorreu com o setor como um todo.

Figura 2: Concentração do sistema de previdência privada aberta

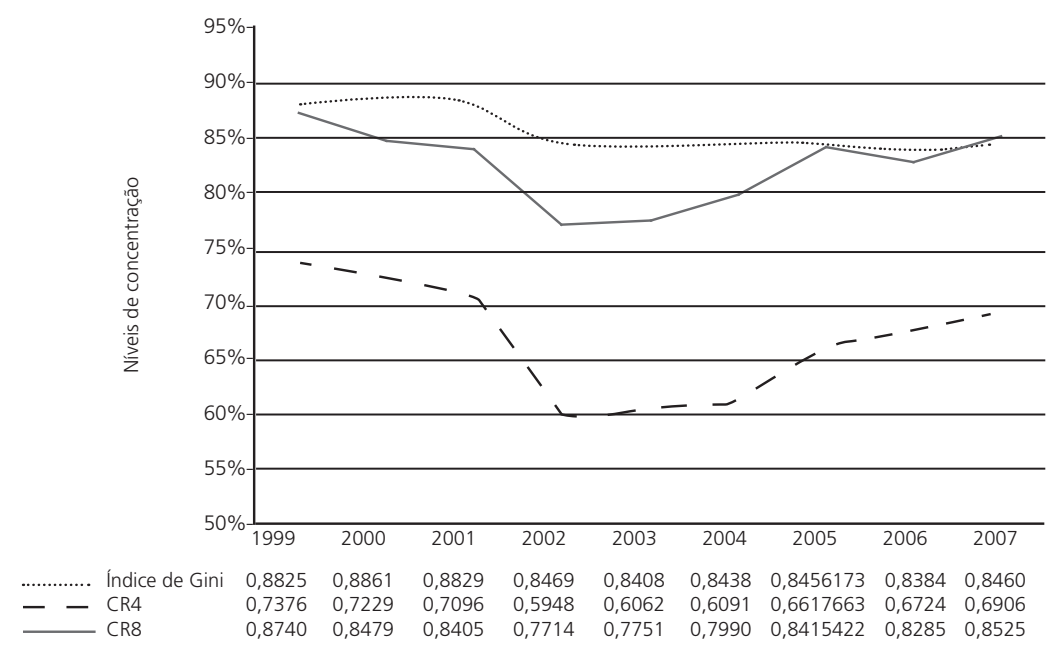


As contradições entre a desconcentração apontada pelo Índice de Gini e a concentração evidenciada pelo Índice de Concentração Parcial não se apresentam como um problema para fins de análise. Os resultados explicam que, apesar de as empresas líderes concentrarem, a cada ano, maiores parcelas do mercado, o restante das empresas divide as arrecadações de maneira cada vez mais igualitária, compensando até mesmo as saídas de empresas. Ou seja, as empresas líderes demonstram uma situação sólida diante das demais, mas no restante do setor ainda há disputas por melhores participações.

A figura 3 apresenta a evolução da participação no mercado das empresas líderes. A primeira linha mostra que as cinco maiores empresas ${ }^{9}$ reduziram suas participações no período 1999-2002, mas aumentaram essa participação após 2002 (crescimento de 18\% entre 2002 e 2007). Já as empresas seguintes, da $6^{\mathrm{a}}$ à $15^{\mathrm{a}}$ em participação, apresentaram movimento oposto, aumentando a fatia no mercado entre 1999 e 2002 e reduzindo esse percentual após 2002 , de $16,79 \%$ e 31,63\%, respectivamente, para os grupos "6 a 10 " "11 a 15 ".

O comportamento das menores empresas do mercado está apresentado na figura 4, que foi construída considerando-se o grupo " 1 a 5 " incorporando as cinco menores empresas do mercado, consistindo, agora, em uma análise da base para o topo.

Verifica-se que as cinco menores empresas não apresentaram variação significativa em suas participações no volume arrecadado.

Na base do mercado, contudo, um grupo de empresas menores está conquistando as parcelas do mercado deixadas pelas maiores, apresentando, assim, crescimento no volume arrecadado, a partir de 2001.

Tal comportamento induz à lógica de que está surgindo uma nova e maior "classe média" de empresas atuantes no mercado previdenciário, que, conjugada com a saída de pequenas empresas, fortalece o setor e possibilita sua maturação com empresas fortes e com maiores potenciais para concorrerem entre si.

Em suma, as cinco maiores empresas aumentaram suas fatias no mercado, as 10 seguintes reduziram essa participação e um conjunto de empresas menores vem conquistando maiores parcelas de arrecadação do setor. Daí a explicação da ocorrência de uma concentração, no período analisado, dos índices CR4 e CR8, e uma desconcentração do setor, segundo o Índice de Gini. 
Figura 3: Crescimento da participação das empresas com maiores parcelas do mercado

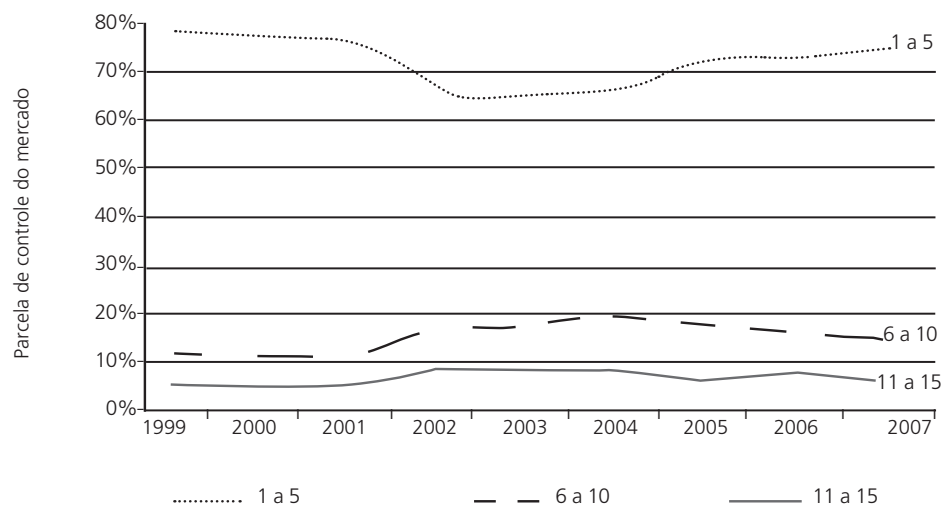

Figura 4: Crescimento da participação das empresas com menores parcelas do mercado

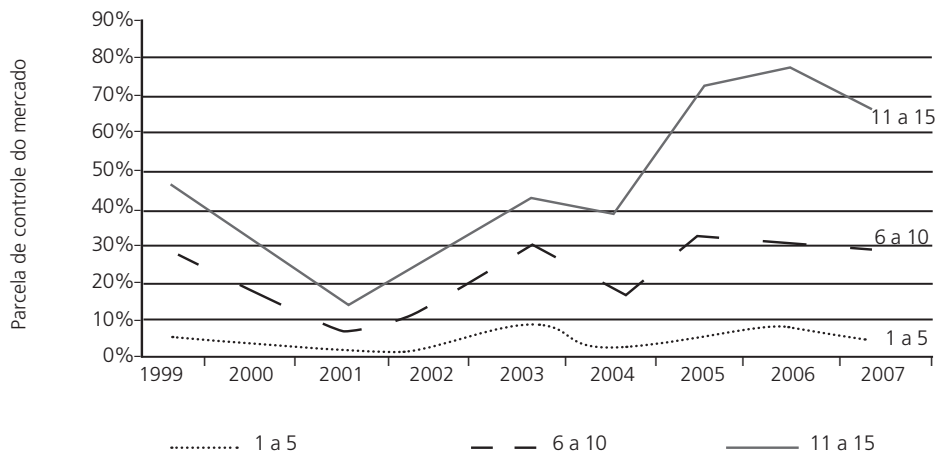

\subsection{Eficiência e tendências estratégicas}

A manutenção das grandes empresas e o crescimento das médias empresas têm como fator relevante as condutas que estas procuram seguir, muitas vezes na tentativa de se diferenciar de outras. As cinco grandes empresas apresentam vantagens que lhes permitem manter e até elevar suas participações no mercado; contudo, as empresas médias não se apresentam, em alguns casos, como operacionalmente ineficientes.

A análise da eficiência das empresas atuantes no sistema de previdência privada aberta, na tentativa de explicar melhor o processo do setor e de comprovar outros estudos, dividiu as DMUs em sociedades seguradoras e em Entidades Abertas de Previdência Complementar - EAPCs. 
Das 18 DMUs eficientes, 11 são seguradoras, e das 20 empresas com maior representatividade no mercado apenas duas não são seguradoras.

Dentre as 25 EAPCs, apenas sete demonstraram resultados eficientes. Essa ineficiência é identificada como resultado de maiores gastos operacionais, de falta de ligação com outras instituições que ofereçam as facilidades operacionais e de ganhos que são oferecidos às seguradoras.

As causas da ineficiência das EAPCs, também, podem ser depositadas na sua reduzida participação nas contribuições retidas do setor, cuja soma não chega a igualar ao volume da quarta maior seguradora do mercado. Além disso, apenas uma das entidades participa de quase metade de todo o volume arrecadado. A baixa parcela de controle do mercado das EAPCs não permite ganhos de escala como ocorre com as seguradoras.

Para melhor compreensão do setor previdenciário, é necessário destacar o desempenho das sociedades seguradoras, dada a sua importância nesse ramo de atividade. Tal análise tem como suporte a visão de Camp (1993), que destaca a importância de obter medidas comparativas entre empresas que possuem um mesmo escopo e situações parecidas, para que as metas alcancem um patamar real e de valor para a instituição. Baseado nessa ideia de comparar os semelhantes, fez-se uma análise dos benchmarking das seguradoras, assim como das estratégias mais destacadas entre elas.

\subsubsection{Seguradoras}

Uma característica interessante das seguradoras com atuação em planos de previdência privada é que elas operam com o principal serviço substituto desses planos, os seguros de vida.

As seguradoras, além de não terem a preocupação com a substituição dos produtos, ainda se privilegiam com menores custos administrativos, dentre outros gastos, proporcionados pelo aproveitamento de um mesmo corretor com possibilidade de atender tanto ao público voltado para o seguro quanto àquele que procura um plano de previdência. Podem-se beneficiar, ainda, do cliente indeciso, possibilitando-lhe a escolha do produto mais adequado às suas necessidades.

As seguradoras possuem ainda uma vantagem não partilhada pelas EAPCs, que consiste na maior facilidade de entrada e saída desse mercado. Uma seguradora comercializa, além dos planos previdenciários, planos de 
seguros. As exigências técnicas e estruturais e a comercialização desses planos se assemelham, possibilitando que a entrada da seguradora no mercado de previdência não gere dificuldades, pois já existe toda uma estrutura montada. Da mesma forma, sua saída desse mercado não gera grandes prejuízos, já que a estrutura montada para a comercialização dos planos previdenciários poderá ser usada para a área de seguro. Essa mecânica ajuda a reduzir as barreiras à entrada e saída, fator essencial para um mercado contestável.

Entre as seguradoras, a estratégia mais usada é, sem dúvida, a ligação com instituições bancárias, o que facilita a questão de distribuição e alcance de clientes. A ligação, como a venda dos seguros de vida, permite a redução de custos com funcionários e ainda com instalações, já que as usadas para as operações da instituição bancária são utilizadas completamente para a venda dos produtos previdenciários.

Essa estratégia se apresenta de grande importância no setor. Observa-se que as três seguradoras com maior controle do mercado apresentam ligações diretas com as três marcas mais fortes do setor financeiro: Bradesco, Banco do Brasil e Itaú (Albuquerque, 2008). Segundo Borges (2006), a Sul América Seguros, uma seguradora independente, apresentou a maior contratação de corretores especializados como forma alternativa de atuação em face das seguradoras que contam com as facilidades de uma extensa rede bancária.

A tabela 2 apresenta outra forma de atuação, que permite uma concorrência indireta com aquelas que se apresentam como líderes, como foi aconselhado por Porter (1996). Novamente, o ranking da parcela assegurada da empresa no mercado foi contraposto à eficiência do processo de produção. Como mencionado anteriormente, há uma divisão entre as seguradoras que estão associadas a sistemas bancários e aquelas independentes, com implicações sobre a participação no mercado.

O que chama a atenção na tabela 2 é a concentração de empresas eficientes entre aquelas consideradas de médio tamanho, ${ }^{11}$ que ocupam da $10^{\mathrm{a}}$ à $17^{\text {a }}$ posição. Esse resultado complementa a discussão sobre a desconcentração do mercado apresentada anteriormente. ${ }^{12}$ Ou seja, o fato de elas serem as mais eficientes faz com que tenham a possibilidade de permanecerem $\mathrm{e}$ disputarem mercado com as grandes empresas. O nível 100\% indica que essas são as mais eficientes do setor, considerando-se o desempenho relativo de todas as empresas sob análise. 


\begin{tabular}{|c|c|c|c|}
\hline \multicolumn{2}{|c|}{ Posição contribuição } & \multirow{2}{*}{$\begin{array}{c}h \\
2,1373 \\
\end{array}$} & \multirow{2}{*}{$\begin{array}{c}\text { Eficiência }^{10} \\
46,79 \%\end{array}$} \\
\hline 1 & seg & & \\
\hline 2 & seg & 1,1396 & $87,75 \%$ \\
\hline 3 & seg & 1,5578 & $64,19 \%$ \\
\hline 4 & seg ñ banc & 1 & $100,00 \%$ \\
\hline 5 & seg & 1,1532 & $86,72 \%$ \\
\hline 6 & seg & 1,3027 & $76,76 \%$ \\
\hline 7 & seg ñ banc & 1,1361 & $88,02 \%$ \\
\hline 8 & seg ñ banc & 1,6393 & $61,00 \%$ \\
\hline 9 & seg & 2,5487 & $39,24 \%$ \\
\hline 10 & seg & 1 & $100,00 \%$ \\
\hline 11 & seg & 1 & $100,00 \%$ \\
\hline 12 & seg ñ banc & 1 & $100,00 \%$ \\
\hline 13 & seg & 1 & $100,00 \%$ \\
\hline 14 & seg ñ banc & 1 & $100,00 \%$ \\
\hline 15 & seg ñ banc & 1 & $100,00 \%$ \\
\hline 16 & seg & 1 & $100,00 \%$ \\
\hline 17 & seg & 1 & $100,00 \%$ \\
\hline 18 & seg & 1,6624 & $60,15 \%$ \\
\hline 19 & seg ñ banc & 1,1523 & $86,78 \%$ \\
\hline 20 & seg & 1,8368 & $54,44 \%$ \\
\hline
\end{tabular}

Outro ponto de destaque neste estudo é a baixa taxa de eficiência alcançada pela empresa líder do mercado: menos de $47 \%$ (o que indica uma possibilidade de aumento na produção de quase $114 \%) .{ }^{13}$ Essas empresas apresentaram resultados semelhantes em anos anteriores (2005 e 2006), assim como o maior número de empresas médias eficientes.

Foram separadas ainda as seguradoras entre ligadas ou não a um setor bancário. Sobre estas últimas, a eficiência se apresenta também como estratégia alternativa. A empresa que apresentou o melhor nível de eficiência dentre todas foi a DM4, uma seguradora sem ligações com bancos.

A sétima e a oitava posição são ocupadas por seguradoras sem ligações bancárias e demonstram ineficiência. Contudo, elas evidenciam a importância de pertencer a um grupo de seguros forte, com representatividade no mundo e com experiência. Apesar de não estarem ligadas aos bancos, ambas e também a empresa ocupante da quarta posição possuem grupos estrangeiros de expressão no mercado mundial. É o capital estrangeiro e a experiência no ramo que indicam sua relevância para o mercado. 


\section{CONCLUSÕES}

O número de empresas, principalmente das seguradoras, aumentou muito desde 1994. O principal fator macroeconômico responsável por esse fenômeno foi a estabilização da economia, com a redução das taxas de inflação, que permitiu ao público pensar em investimentos de longo e longuíssimo prazo, como são caracterizados os investimentos previdenciários.

Assim como o número de empresas, os índices indicativos de desempenho do setor também demonstraram grande crescimento, tornando o mercado de previdência um dos que apresentaram as maiores taxas de crescimento no Brasil nos últimos anos.

Foi observada, a partir de 2001, uma redução no número de novas empresas a cada ano, um resultado comum para um mercado novo e com altas taxas de crescimento. Em um primeiro momento, houve estímulo à entrada de muitas novas empresas; contudo, após um período de consolidação e maturação das empresas e de suas estratégias, muitas acabaram por sair do mercado pela dificuldade de acompanhar a evolução do setor.

Apesar de o setor demonstrar quedas no número de empresas entrantes, ele apresenta características de um setor contestável, com liberdades legais à saída e à entrada de empresas. Os órgãos responsáveis demonstram uma preocupação com a forma de atuação das empresas, prezando pela credibilidade e segurança do setor. Essa preocupação torna-se um fator positivo para a redução do poder de mercado das empresas, proporcionando maior semelhança entre os produtos e as empresas.

Contudo, a forma de atuação das próprias empresas estabelece barreiras que dificultam novas entradas. As grandes empresas se caracterizam como empresas sólidas, que conquistam, a cada ano, maior parcela do mercado. Seus diferenciais se encontram na propaganda, já que seus nomes estão vinculados a grandes redes bancárias.

A questão das ligações ao setor bancário apresenta-se como um fator indesejável, quando se analisam as principais empresas do setor. Essas empresas detêm grande parcela do mercado e demonstram ganhos a cada ano, porém não se apresentam como empresas eficientes. Tal fenômeno pode ter duas possíveis explicações. A primeira relaciona-se ao fato de que, para os grandes bancos, o ramo de seguro é apenas mais um produto dentro da 
busca de diferenciação de seus vários produtos, não precisando ser eficiente para concorrer no mercado, uma vez que os clientes o procuram pelo nome já consolidado da empresa. A segunda refere-se à falta de especialização dos corretores, uma vez que os bancos utilizam os funcionários existentes, sem necessariamente serem especializados em seguros.

A ligação das seguradoras com entidades bancárias, assim, implica promoção de maior concentração no mercado e desestímulo para a empresa procurar melhores resultados em termos de eficiência. Apesar de muitas vezes serem consideradas malévolas ao mercado, as leis antitrustes ou leis de defesa da concorrência têm, por teoria, o objetivo de

garantir a existência de condições de competição, preservando ou estimulando a formação de ambientes competitivos com vistas a induzir, se possível, maior eficiência econômica como resultado do funcionamento dos mercados (Mello, 2002, p. 485).

Em certos países, como os EUA, essa forma de ligação é proibida, sendo considerada venda casada.

$\mathrm{O}$ acesso aos canais de distribuição é uma barreira à entrada, passível de ser vencida pela ligação com o setor bancário, mas que dificulta a atuação de empresas independentes e obriga as novas empresas a entrarem já com uma ligação forte com o setor bancário, o que representa uma barreira à sua entrada. Esse fator constitui a maior barreira à contestabilidade do setor.

O setor apresenta altas taxas de concentração, podendo ser caracterizado como um oligopólio. Contudo, vem apresentando índices de desconcentração que ocorrem principalmente entre as empresas que disputam parcelas medianas das contribuições gerais do setor. A desconcentração ocorre mais intensamente entre as seguradoras.

Apesar de a eficiência no processo produtivo não ser fator determinante para o desempenho da empresa, ela está relacionada com a desconcentração do setor. A eficiência passa a ser uma estratégia na tentativa de vencer os grandes nomes das grandes seguradoras, proporcionando uma concorrência não direta entre elas.

As sociedades seguradoras apresentaram maior eficiência que as EAPCs, muito disso ocorrendo pelo aproveitamento das instalações e do pessoal que atua na comercialização de outros produtos, como os seguros de vidas, que diluem o valor das despesas administrativas em meio a maior volume 
de transações. Essa vantagem ocorre de modo diferenciado nos grupos bancários e nos grupos seguradores, possuindo este último uma estrutura para a venda de produtos semelhantes aos planos de previdência, enquanto para os bancos a comercialização é mais diversificada, com menor grau de especialização dos funcionários e do sistema em geral.

Em suma, a organização interna do setor parece passar por uma nova fase, que surgiu a partir de 2002, com as cinco maiores empresas firmando suas posições e outras procurando encontrar melhores estratégias para ganhar posições no mercado. Com a ajuda das regras vigentes, têm conseguido concorrer de forma mais igualitária. Contudo, algumas regras devem ser reavaliadas, haja vista que determinadas estratégias, como a associação com o setor bancário, ainda dificultam maior concorrência no setor, permitindo que empresas mais ineficientes continuem a aumentar sua participação no mercado. O menor número de empresas entrantes e a contínua saída de outras marcam essa fase, em que a experiência e a conduta fazem a diferença para a permanência e crescimento no setor previdenciário.

\section{NOTAS}

1. Citado em Arruda (2004, p. 67).

2. Com relação à contribuição dos planos previdenciários arrecadados.

3. Data Envelopment Analysis.

4. Decision Making Unit é o termo utilizado, pois o modelo pode ser aplicado a qualquer unidade que tome decisões sobre a forma de atuação, não se restringindo apenas às empresas.

5. Iniciais dos nomes dos seus criadores: Banker, Charnes e Cooper.

6. A análise é voltada apenas à seguradora, considerando-se rendimentos constantes pela maior semelhança no porte das empresas analisadas.

7. Consideraram-se, para as seguradoras, os insumos e produtos referentes à comercialização dos seguros de vida.

8. As entradas e saídas são informações não disponibilizadas pelos órgãos competentes. Buscou-se, aqui, identificar como atuante ou não as instituições que mantinham provisões de operações de previdência em cada ano. Por esse motivo, uma instituição poderá cessar a oferta de planos previdenciários em um ano, mas ainda manter provisões para garantia de alguns planos remanescentes.

9. Foram analisadas as cinco maiores empresas, e não as quatro maiores, que determinaram o CR4, porque foram aquelas que apresentaram o mesmo comportamento nos dois períodos analisados. 
10. Sendo eficiência igual a $1 \backslash \mathrm{h}$.

11. Considerando a parcela de controle de mercado.

12. As posições das seguradoras na tabela 2 não são as mesmas apresentadas na discussão sobre a concentração do setor.

13. $=(2,1373-1)^{\star} 100$

\section{REFERÊNCIAS BIBLIOGRÁFICAS}

ABOLINS, A. C. Estratégias das empresas que atuam no mercado de previdência complementar aberta no Brasil. São Paulo: FGV, 2000. 41 p. Iniciação Científica - CNPq. Fundação Getulio Vargas.

ALBUQUERQUE, $\mathrm{V}$. Brasil tem cinco marcas entre as 500 maiores do setor financeiro mundial. In: Folha on line, acesso 26 fev. 2008. <http://www1.folha.uol.com.br/folha/dinheiro/ ult91u376170.shtml>

ARRUDA, M. G. C. A previdência privada aberta como relação de consumo. São Paulo: LTR, 2004. p. 230.

BAIN, J. S. Industrial Organization. Berkeley: University of Califórnia, 1959. 643 p.

BAUMOL, W. J. Contestable Markets: An Uprising in the Theory of Industry Structure. American Economic Review, v. 72, n. 1, mar. 1982.

BORGES, E. De cara nova. In: Revista Conjuntura Econômica, v. 61, n. 5, p. 22-45, maio 2007.

. O futuro está presente. In: Revista Conjuntura Econômica, v. 60, n. 1, p. 14-27, maio 2006.

BRASIL. Constituição, 1988. Constituição da República Federativa do Brasil, 1988. São Paulo: Ed. Revista dos Tribunais, 1989.

CAMP, R. C. Benchamarking: o caminho da qualidade total. São Paulo: Pioneira, 1993.

CARVALHO, J. L. Regulamentação na indústria de seguros: reservas técnicas, derivativos e seguro apólice. Revista Brasileira de Risco e Seguro, v. 1, n. 2, p. 1-25, 2006.

CIRCULAR DA SUSEP N. 260, 8 JUL. 2004. Regulamenta os atos societários, a constituição, a transferência do controle acionário e a reavaliação periódica dos imóveis das sociedades seguradoras, das sociedades de capitalização e das entidades de previdência complementar aberta e dá outras providências. Disponível em: < http://www.susep.gov.br/textos/ circ260.pdf>. Acesso em 10 fev. 2008.

DECRETO-LEI N. 73, de 21 DE NOVEMBRO de 1966. Dispõe sobre o Sistema Nacional de Seguros Privados, regula as operações de seguros e resseguros e dá outras providências. Disponível em: <http://www.planalto.gov.br/ccivil/Decreto-Lei/Del0073.htm> Acesso em 25 de Janeiro de 2008.

FARIA, I. V. DE, Estrutura competitiva do mercado segurador brasileiro. Revista Brasileira de Seguros, v. 2, n. 4, p. 17-41, 2007.

FENAPREVI, Federação Nacional Previdência Privada e Vida. Disponível em: <http://www. fenaprevi.org.br>. 
FENASEG, Informe Anual do Mercado Segurador Brasileiro. Rio de Janeiro, 2006. 88p. . Informe Anual do Mercado Segurador Brasileiro. Rio de Janeiro, 2004. 96p.

GHILARDI, W. J. Avaliação não paramétrica de desempenho do setor bancário brasileiro. Santa Maria/RS: UFSM, 2006. 86p. (Dissertação de Mestrado em Administração) — Universidade Federal de Santa Maria.

GOMES, A. P.; BAPTISTA, A. J. S. Análise envoltória de dados: Conceitos e modelos básicos. In: SANTOS, M. L. dos; VIEIRA, W. C. (Ed.). Métodos quantitativos em economia. Viçosa, UFV, 2004. p. 121-160.

JARDIM, M. A. C. A previdência Social e o mercado de previdência privada: um olhar sociológico. In: ENCONTRO ABET, 8. São Paulo, 2003.

KATO, J. M. Estratégia competitiva e avaliação de desmpenho aplicados a uma empresa de previdência privada aberta no Brasil. Florianópolis: UFSC, 2000. 125p. (Dissertação de Mestrado em Engenharia de Produção) - Universidade Federal de Santa Catarina.

MASON, E. Price and Production Policies of Large-Scale Enterprise. American Economic Review, v. 29, mar. 1939.

MELLO, M. T. L. Defesa da Concorrência. In: KUPFER, D.; HASENCLEVER L. (Org.). Economia Industrial: fundamentos teóricos e práticos no Brasil, 2. ed. Rio de janeiro: Campus, 2002.

PORTER, M. E. What is strategy? Harvard Business Review, p. 61-78, nov./dec. 1996.

Como as forças competitivas moldam a estratégia. In: PORTER, M. E. Competição: estratégias competitivas essenciais. Rio de janeiro: Campus, 1979, p. 27-45. 1999.

MOURA, R. L.; TAFNER, P.; JESUS FILHO, J. Testando a propriedade redistributiva do sistema brasileiro: uma abordagem semiparamétrica. In: TAFNER, P., GIAMBIAGI, F. (Orgs.). Previdência no Brasil: debates, dilemas e escolhas. Rio de Janeiro: Ipea, 2007. p. 349-400.

SILVA, A. C. M. da. Testes de eficiência na área de seguradoras, previdência privada aberta e capitalização no mercado brasileiro em relação ao períodos de 2000 a 2003: uma abordagem através de testes não paramétricos e modelos de Lógica Nebulosa. Revista Brasileira de Seguros, Rio de Janeiro, v. 1, n. 2, p. 89-119, mar. 2006.

AZEVEDO, G. H. W. de. Eficiência e sobrevivência: binômio fundamental para a previdência privada aberta. Revista Brasileira de Seguros, Rio de Janeiro, v. 1, n. 0, p. 6889, dez. 2004.

SUSEP, Superintendência de Previdência Privada. Boletim estatístico. $<$ http://www.susep. gov.br $>2008$. 